\title{
Areas of Climate Stability of Species Ranges in the Brazilian Cerrado: Disentangling Uncertainties Through Time
}

\author{
Levi Carina Terribile ${ }^{1 *}$, Matheus Souza Lima-Ribeiro ${ }^{1}$, Miguel Bastos Araújo,3,4, Nair Bizão, \\ Rosane Garcia Collevatti ${ }^{6}$, Ricardo Dobrovolski , Amanda Assis Franco ${ }^{1}$, François Guilhaumon ${ }^{3}$, \\ Jacqueline de Souza Lima6, Devanir Mitsuyuki Murakami ${ }^{5}$, João Carlos Nabout', \\ Guilherme de Oliveira ${ }^{1}$, Leciane Karita de Oliveira ${ }^{6}$, Suelen Gonçalves Rabelo ${ }^{6}$, \\ Thiago Fernando Rangel ${ }^{7}$, Lorena Mendes Simon ${ }^{7}$, Thannya Nascimento Soares ${ }^{6}$, \\ Mariana Pires de Campos Telles ${ }^{6}$ \& José Alexandre Felizola Diniz-Filho ${ }^{7}$
}

${ }^{1}$ Laboratório de Macroecologia, Universidade Federal de Goiás - UFG, Campus Jataí, Jataí, GO, Brasil

${ }^{2}$ Department of Biogeography and Global Change, National Museum of Natural Sciences, CSIC, Madrid, Spain

${ }^{3}$ Cátedra Rui Nabeiro de Biodiversidade, CIBIO, Universidade de Évora, Évora, Portugal

${ }^{4}$ Center for Macroecology, Evolution and Climate, University of Copenhagen, Copenhagen, Denmark

${ }^{5}$ Universidade Federal do Mato Grosso - UFMT, Barra do Garça, MT, Brasil

${ }^{6}$ Laboratório de Genética \& Biodiversidade, Universidade Federal de Goiás - UFG, Goiânia, GO, Brasil

${ }^{7}$ Departamento de Ecologia, Instituto de Ciências Biológicas - ICB, Universidade Federal de Goiás - UFG, Goiânia, GO, Brasil

${ }^{8}$ Universidade Estadual de Goiás - UEG, Unidade Universitária de Ciências Exatas e Tecnológicas, Anápolis, GO, Brasil

\begin{abstract}
Recognizing the location of climatically stable areas in the future is subjected to uncertainties from ecological niche models, climatic models, variation in species ranges responses, and from the climatic variation through time. Here, we proposed an approach based on hierarchical ANOVA to reduce uncertainties and to identify climatically stable areas, working with Cerrado tree species as a model organism. Ecological niche models were generated for 18 Cerrado tree species and their potential distributions were projected into past and future. Analyses of the sources of uncertainties in ensembles hindcasts/forecasts revealed that the time component was the most important source of variation, whereas the climatic models had the smallest effect. The species responses to climate changes do not showed marked differences within each time period. By comparing past and future predictions, a single continuous climatically stable area was identified, which should be considered as a potential improvement for spatial prioritization for conservation.
\end{abstract}

Key words: Climate Change, Climatically Stable Areas, Ensemble Forecasting, Ecological Niche Models, Systematic Conservation Planning

\section{Introduction}

There is growing evidence that areas exposed to long-term climate stability (refugia) have a critical role in promoting persistence of biodiversity particularly when regional or global climate conditions change (e.g., Graham et al. 2006). Climatically stable areas in the past are frequently associated with high levels of diversity and endemism (e.g., Haffer 1969; Fjeldså et al. 1999; Araújo et al. 2008). In the future, areas of high climatic stability may perform a similar role protecting current biodiversity and thus they are considered

\footnotetext{
*Send correspondence to: Levi Carina Terribile

Laboratório de Macroecologia, Universidade Federal de

Goiás - UFG, Campus Jataí, Jataí, GO, Brasil

E-mail: levicarina@gmail.com
}

to be very important as buffers to the impacts of rising global temperatures and wide climate changes in the $21^{\text {st }}$ century (Williams et al. 2008; Werneck et al. 2012). Identifying these areas and reducing the uncertainties about their location is a very useful task for biodiversity conservation because of the drastic shifts in the current distribution of climatically suitable areas for species and ecological communities that are expected to occur due to future climate changes.

A common approach to explore the location of climatically suitable areas in the future (Garcia et al. 2012; Loyola et al. 2012) involves the use of Ecological Niche Models (ENMs; also called Species Distribution Models - but see Araújo \& Peterson (2012) and Peterson \& Soberón (2012)). These 
models correlate current climate and known species occurrences to predict the potential distribution of the species into the future, being now widely used to predict past distributions (e.g., Nogués-Bravo et al. 2008) and identify areas of long-term climate stability (historical refugia) (e.g., Werneck et al. 2012), as well as many other applications (see Peterson et al. 2011 for a recent review). However, there are many uncertainties associated with the use of ENMs for forecasting or hindcasting climatically suitable areas, arising from differences in methods used for ENMs (e.g., Pearson et al. 2006; Diniz-Filho et al. 2010), the variety of simulations from Atmosphere-Ocean General Circulation Models (AOGCM) and greenhouse emission scenarios (Beaumont et al. 2005), and the cut-offs used to transform estimates of suitabilities from the models into presence and absence (Nenzén \& Araújo 2011). The methodological uncertainties have been widely discussed in the literature (e.g., Heikkinen et al. 2006) and led to the proposition of the ensemble approach (Araújo \& New 2007), whereby several models are generated and emerging consensuses across models identified. In addition to methodological uncertainties, there are several ecological uncertainties that constrain the degree of equilibrium of species with current climate (e.g., Munguía et al. 2012). Species have unique multidimensional fundamental niches but several factors can cause portions of this niche to be unoccupied. For instance, shifting climate conditions and break down of dispersal barriers can lead species to expand ranges into previously unoccupied portions of the fundamental niche. Given this process of reshuffling of geographical ranges, some species may co-occur at a given location in a given moment in time, but not in others (Williams \& Jackson 2007). The interplay between climate change, species individual responses to climate change and biotic interactions also generates important levels of uncertainty due to ecological factors.

This interplay of causes of uncertainty makes necessary a critical assessment of the shift of climatically suitable areas through time (Graham et al. 2010; Ashcroft 2010), implying that historically stable areas (refugia), which are potentially important for biodiversity conservation at present may be unlikely to remain suitable in the future. Consequently, integrated approaches that combine the current location of past refugia with the identification of climatically suitable areas in the future are more likely to reach the aim of preserve biodiversity facing an uncertain future. Here we propose an approach based on a hierarchical ANOVA that allow us to reduce methodological uncertainty and identify climatically stable areas based on ensembles of hindcasts/forecasts. We demonstrate how this approach can be used to define climatically stable regions through time, delimiting a common area of suitable climates for a set of selected Brazilian Cerrado tree species, by combining past, current and future geographic projections of species' niche. Our protocol also evaluates the relative effects of different sources of uncertainties, including the methodological ones (i.e., from ENMs and AOGCMs) and those from individualistic responses of species' geographical range and from variation through time.

\section{Material and Methods}

\section{General approach}

Our analytical protocol involved three main steps: 1) inferring baseline species potential distributions by means of ENMs fitted for each species using present climatic conditions and then projecting potential distributions into past and future climatic scenarios; 2) combining all model predictions for each species in each time period to obtain and map overall ensembles; and 3) partitioning and mapping the sources of uncertainty from species range shifts, time, and methodological components. The novelty of the approach resides in the exploration of uncertainties among species and time periods after controlling for methodological (ENMs and AOGCMs) effects. Finally, we applied this new protocol to identify areas of overlapping climate stability throughout time (i.e., past, present, and future) in the Cerrado biome.

\section{Species and climate data}

We selected 18 tree species based on their high floristic importance in the Cerrado biome (Ratter et al. 2003) and that are target to population genetic analyses in the GENPAC research network (see acknowledgments). Species analyzed here were Anacardium occidentale, Annona crassiflora, Hancornia speciosa, Tabebuia aurea, Handroanthus ochraceus, Caryocar brasiliense, Dalbergiamis colobium, Dimorphandra mollis, Dipteryx alata, Hymenaea stigonocarpa, Pterodone marginatus, Stryphnodendro nadstringens, Byrsonima cydoniifolia, Byrsonima verbascifolia, Eugenia dysenterica, Qualea grandiflora, Qualea parviflora and Vochysia thyrsoidea. Using a grid of $0.5^{\circ} \times 0.5^{\circ}$ of latitude and longitude, we modeled species niche and projected distributions across the entire Neotropical region, because some species' occurrence extrapolates the limits of the Cerrado biome (see Table S1, in Additional Supporting Information available at www.abeco.org.br, for the list of species, number of records and sources of occurrence data - see also Giovanni et al. (2012) for procedures used to select records from these databases). We obtained the climate layers and characterized the environmental space for ENMs using climatic simulations from pre-industrial (representing current climate conditions), Last Glacial Maximum (LGM, 21,000 years ago - $21 \mathrm{ky} \mathrm{BP)} \mathrm{and} \mathrm{future} \mathrm{(2080-2100,} \mathrm{20-year}$ mean; hereafter 'end-of-century' - EOC), derived from four coupled Atmosphere-Ocean General Circulation Models (AOGCM) - CCSM4, GISS-E2-R, MIROC-ESM and MRI-CGCM3. We downloaded climate variables from AOGCM outputs (monthly simulation for precipitation, and mean, maximum and minimum temperature), which were downscaled to the same grid and used to compute the full range of bioclimatic variables defined in the WorldClim 
database (see <http://www.worldclim.org/bioclim > and Additional Supporting Information for details). These AOGCMs were selected because for them there are compatible projections for past, current and future climate. We then selected five variables (annual mean temperature, temperature annual range, precipitation of wettest month, precipitation of driest month, and precipitation of warmest quarter) out of 19 bioclimatic variables using a factor analysis with Varimax rotation based on the correlation matrix among variables to minimize collinearity problems when building the ENMs. Along with these variables, we also include subsoil pH (30-100 cm; from Harmonized World Soil Database - version 1.1, FAO et al. 2009) in all time steps as a constraint variable to improve the ENMs for tree species. Details about AOGCMs, bioclimatic variables and the procedures to build the climate layers and Factor Analyses are provided in Additional Supporting Information, Tables S2 and S3.

\section{ENMs, ensembles, and uncertainties}

The ENMs for each species were obtained using 14 algorithms, including methods for presence-only and presence-absence data, which are integrated in the computational platform BIOENSEMBLES (see Additional Supporting Information Table S4 for implementation and computational details of the methods used here). Methods used were BIOCLIM, Ecological Niche Factor Analysis (ENFA), Euclidian Distance (ED), Gower Distances (GD), Mahalanobis Distances (MD), Genetic Algorithm for Rule Set Production (GARP), Generalized Linear Models, Maximum Entropy (Maxent), Generalized additive models (GAM), Flexible Discriminant Analysis (FDA), Multivariate adaptive regression splines (MARS), Generalized boosted models (GBM), Neural Networks (ANN) and Random Forest (RNDFOR). In short, models were first generated for pre-industrial scenario and then projected onto LGM and EOC to predict the species geographical range for these periods. Because absence data are not available, we randomly selected pseudo-absences across the Neotropical grid to fit the model, keeping prevalence equal to 0.25 (see Santika 2011). For each algorithm, models were built using a calibration subset of $75 \%$ of the presence cells selected at random and then evaluated with the remaining $25 \%$, repeating this procedure 50 times. The 50 models were then used to generate occurrence maps based on thresholds established by the ROC curve. Finally, species' frequencies of occurrence in each Neotropic grid cell at each period were obtained based on the 50 occurrence maps. Models with poor performance were eliminated from these frequency ensembles based on True Skill Statistics (TSS) (i.e., models with TSS $<0.5$ were eliminated) (see Diniz-Filho et al. 2009).

Our modeling procedure resulted in 1008 frequency maps (i.e., 14 ENMs * 4 AOGCMs * 18 species) for each time period. To disentangle and map the uncertainties in hindcasts/forecasts ensembles, we performed an ANOVA for each grid cell using frequency of occurrence as response and nesting methodological components within species and time components in different levels (see Figure 1). The methodological uncertainties were obtained using a factorial ANOVA design (ENM, AOGCM, and their interaction) nested within species that are also nested within time periods. Thus, the predictive maps combining ENMs and AOGCMs represented replicates within species and time and expressed the uncertainty about species geographical ranges in each time period. Similarly, the variance across species maps expressed the uncertainty in their distributional ranges in the Cerrado within a given time.

Finally, to define areas of long-term climate stability across the Cerrado we converted the consensus maps (i.e., frequency of occurrence of each species from the ensemble of ENMs and AOGCMs) in occurrence maps using a frequency threshold of 0.5 . A cell was then considered climatically stable if a give species was predicted to occur in that cell during the three time periods (i.e., present, LGM and EOC). Therefore, the proportion of species in each grid cell that are present in the three periods expresses its relative stability.

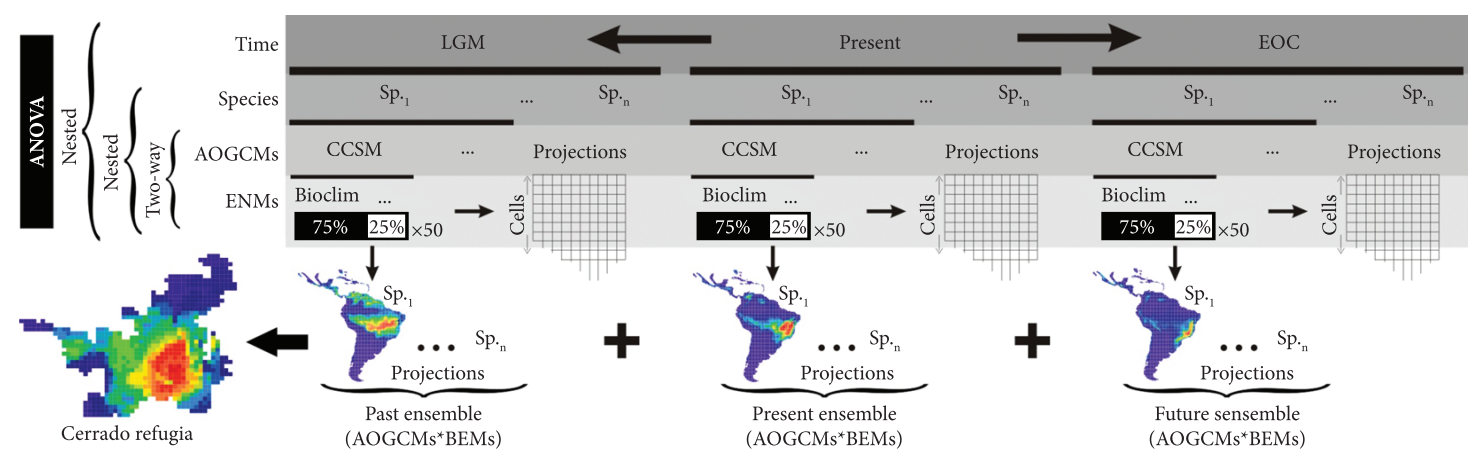

Figure 1. Schematic representation of the proposed analytical protocol. Occurrence maps for each time period - LGM, present and EOC - were generated for each tree species, AOGCM and ENM method based on 50 random replications of calibration (75\%)/ validation (25\%) datasets. A hierarchical ANOVA was applied to disentangle the predictive uncertainties. The methodological uncertainties related to AOGCMs and ENMs were evaluated with a two-way ANOVA, which are nested within species and time. Species and time also represented hierarchical levels of uncertainties. The frequency of species that occurred in the three time periods provided a measure, for each grid cell, of its climate stability, yielding a map of Cerrado refugia. 


\section{Results}

Overall, the spatial distribution of the Cerrado as predicted by the frequencies of occurrence of the 18 modeled tree species for the current time is very similar to the observed geographic limits of this biome. Species distributions in LGM diverge from the current potential distribution of the biome in areas of high suitability northward of Amazonia. Slight differences also suggest that its core area was more north-westerly distributed than currently. Future prediction reveals marked differences, with reduction and south- and eastward displacement of the core area, along with the loss of suitability in most of northern and western portions of the biome (see Figures S1a, S1b and S1c in Additional Supporting Information for details).

The ANOVA (Table 1) indicated that the time component had the highest median proportion (14.58\%) and amplitude (0.00-35.71\%) of the total sum of squares (SS), in comparison with the methodological (i.e., ENM, AOGCM, and the interaction $\mathrm{ENM}{ }^{*} \mathrm{AOGCMs}$ ) and the species components. The lowest effect was observed for the AOGCM component, with a median proportion of $5.10 \%$ and amplitude varying between 1.68 and $23.10 \%$. The distribution of these uncertainties also differed geographically (Figure 2). Conflicting predictions among time periods were mainly concentrated in the central-northern and western portions of biome (attaining 35\% in the SS proportions, Figure 2e). An opposite pattern was observed for AOGCM factor and its interaction with ENM (Figure 2c), with high differences in the northeast and southeast of the biome (maximum value of SS proportion of 23\%), indicating a complementary effect between time and AOGCM components.

The map of stability revealed a single climatically stable area for most species through time (16 out of the 18 species analyzed) covering the central-south of the biome (Figure 3). This pattern results from a gradient effect of species suitability, with values increasing from the edges to the central portions of biome. The location of these refugia largely coincides with the areas of low uncertainties from time component.

\section{Discussion}

Our analytical protocol delineated a shared area of suitable climate for most Cerrado tree species through time, combining past, present and future geographic projections of species ecological niches. In the main, applications of ENMs for conservation purposes have been focused on two diverging approaches: 1) a 'looking forward' approach that seeks for areas of climate suitability in face of future scenarios of climate changes (e.g., Hannah et al. 2007), and 2) a 'looking backward' approach that searches for historical refugia making the assumption that they encompass high biodiversity and endemism and thus must be preserved (e.g., Graham et al. 2006; Werneck et al. 2012). These approaches make the common implicit assumption that the temporal extent they consider (i.e., from present to past or to future periods separately) is sufficient to picture the whole range of climate variation that species can support (Smith \& Boyer 2012). However, there is considerable evidence that the dynamic of climate changes during the Quaternary was different from the changes that are expected in the future, based on current forecasts (Williams \& Jackson 2007). If so, designing reserves based on historical refugia alone is likely to fail to preserve biodiversity in the future. Similarly, selecting future suitable areas based only on present evidences (i.e., without considering climate variations in a deeper temporal perspective) does not ensure that these areas will encompass the full range of climatic conditions experienced by species through time. Here, looking simultaneously in the past and the future, we were able to map those areas across the Cerrado that are most likely to be suitable in the future, taking into account their past history. Therefore, such climatically stable areas should be entered in the process of spatial prioritization for conservation planning of the biome.

Regarding the sources of uncertainties, our results showed that when we apply an hierarchical approach to analyze the sources of variation, we are able to reduce the methodological uncertainties and look more clearly on those uncertainties with ecological meaning (those from time and species' specific responses). This finding indicates that the consensus solution is viable for conservation planning, but requires analysis of species response to climate changes from a wider temporal scale. The largest variance emerging from the time component ( $14 \%$, Table 1), along with the smallest variance from AOGCM (5\%), indicate that the AOGCMs recovered relatively well the climatic dynamic through time (i.e., they correctly predict a climatic gradient from cold conditions in the LGM to warm in the present, and even

Table 1. Median proportions and minimum and maximum of the total sum of squares (SS) from the nested ANOVA performed for each Cerrado cell. The Ecological Niche Model (ENM), Atmosphere-Ocean Global Circulation Model (AOGCM) and their interaction $\left(\mathrm{ENM}^{*} \mathrm{AOGCM}\right)$ are components of methodological uncertainties (and were nested in species component). Species (nested in time) and time represent the variation is species ranges response to climate change and the climatic variation through time, respectively.

\begin{tabular}{lcc}
\hline \multicolumn{1}{c}{ Sources of uncertainties } & Median SS (\%) & Min-Max (\%) \\
\hline ENM [Species] & 12.14 & $6.93-35.09$ \\
AOGCM [Species] & 5.10 & $1.68-23.21$ \\
ENM $^{*}$ AOGCM [Species] & 13.55 & $8.39-23.45$ \\
Species [Time] & 12.09 & $4.43-30.32$ \\
Time & 14.58 & $0.00-35.71$ \\
Residual & 38.83 & $26.06-51.81$ \\
\hline
\end{tabular}



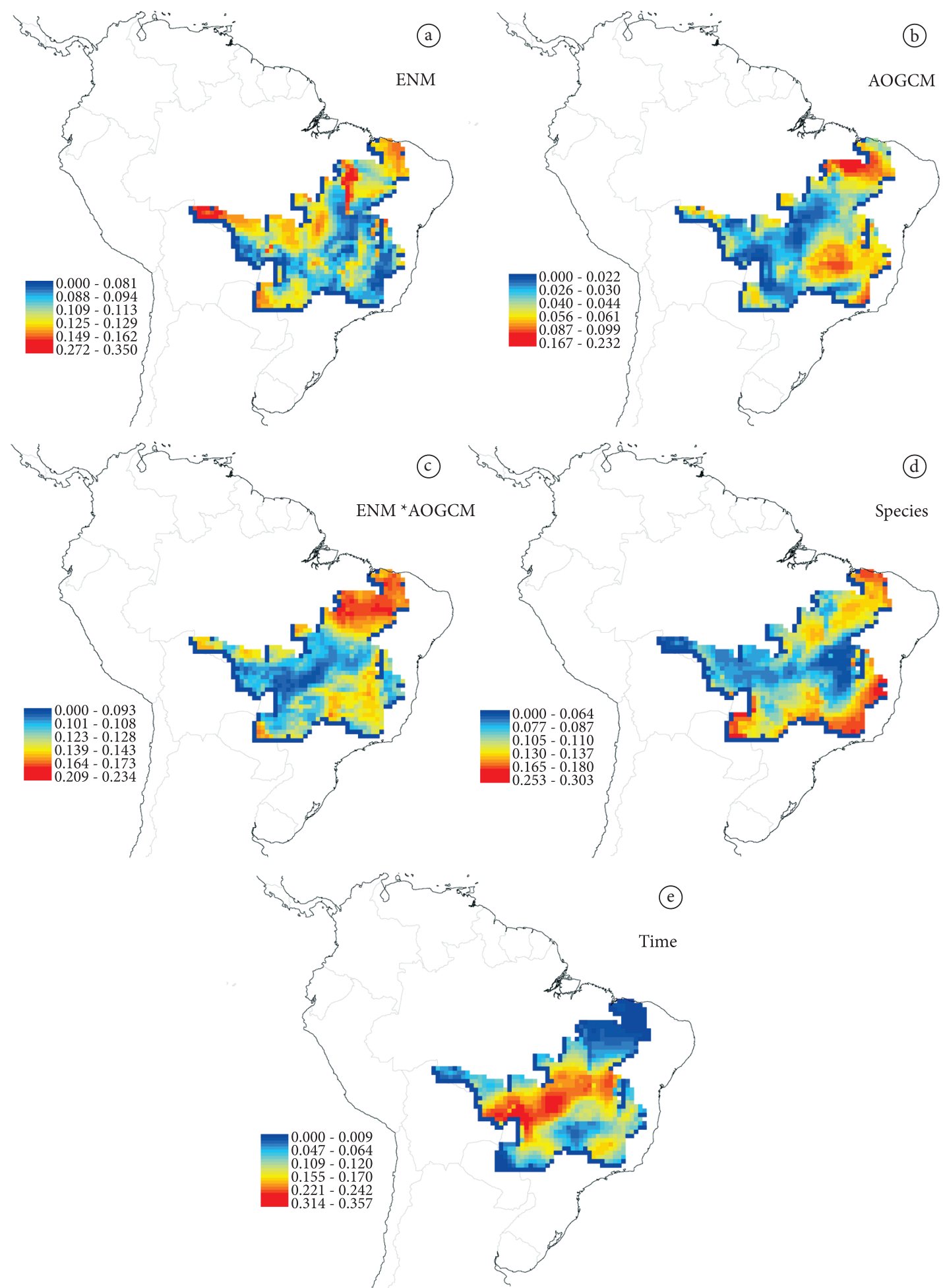

Figure 2. Maps of variance component (relative sum of squares) for the effect of a) Ecological Niche Models (ENMs), b) AtmosphereOcean Global Circulation Models (AOGCM), c) ENM * AOGCM interaction, d) species, and e) time.

warmer in the future), coming near to the 'ideal' prediction (i.e., with reduced methodological uncertainty), in spite of the differences observed among them within a single time period (e.g., Diniz-Filho et al. 2009). However, although the methodological uncertainty from AOGCMs was relatively low, our results showed a substantial variance coming from ENMs (see Table 1), in line with previous studies of Diniz-Filho et al. (2009), Nenzén \& Araújo (2011) and Garcia et al. (2012). In this case, combining predictions from multiple models into a single consensual prediction 


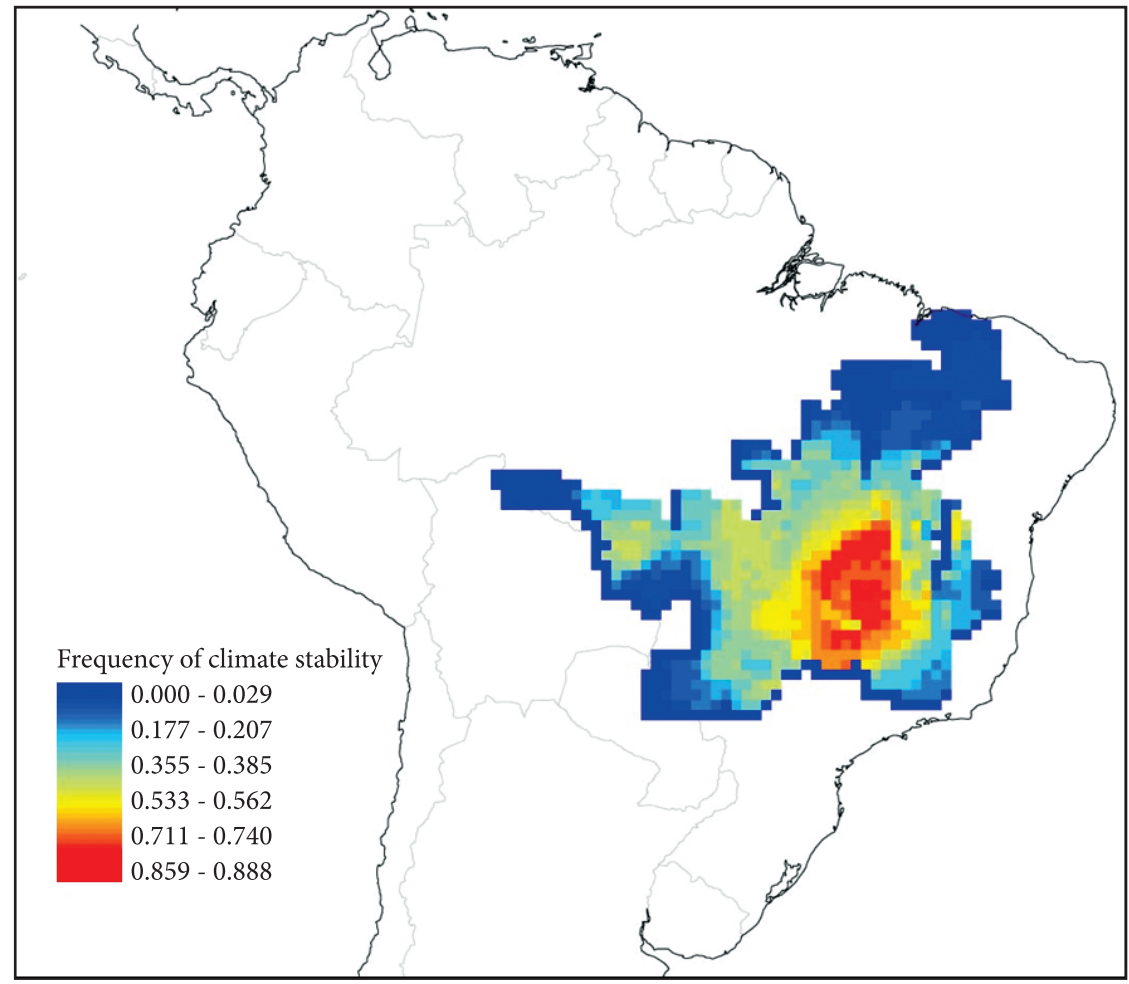

Figure 3. Stability of suitable climates for the 18 Cerrado tree species, estimated as the proportion of species that were present in each Neotropical grid cell in all time periods (LGM, present and EOC), after converting the consensus maps into occurrence maps using a threshold of 0.5 .

represents a defensible solution, particularly when models are used to support conservation decisions in a changing world (Araújo et al. 2011).

The species responses to climate changes do not showed marked differences within each time period, as evidenced by the low median proportion of sum of squares due to species component (12\%). Such result suggests that the species modeled have similar climatic requirements. Therefore, the projected distribution ensembles can reasonably be expected to provide a reliable surrogate to predict the potential limits of Cerrado biome through time. Also, such low relative variation provides important support for approaches that use ensembles of modeled distributional ranges from several species or phylogeographical patterns to evaluate the effect of climate change (e.g., Collevatti et al. 2012a). Despite the low component of species inside times found here (perhaps because we are modeling a relatively homogeneous set of species), we understand that the approach proposed here is more appropriate than the inverse approach of using ENMs for modeling the distribution of whole communities or ecosystems based on the distribution of habitat or biome occurrences (e.g., Graham et al. 2006; Werneck et al. 2012). Biomes are defined according to their vegetation structure and climate and, unless there is a full steady overlap between biome and its species distributions (like a Clements' superorganism), the approach of modeling biomes by climate may be tautological and someway flawed (see Collevatti et al. 2012b).

In conclusion, we recommend looking for species responses to climate changes over a broad time interval (i.e., past and future) to gain confidence on merits of predictions. Equally important is disentangling the different sources of uncertainties associated with species responses to climate change so to assess the reliability of model predictions in which the conservation planning should be based upon. The protocol presented here looks for some of these issues and identified potential refugial areas across the Brazilian Cerrado.

\section{Acknowledgements}

The ideas developed in this work resulted from discussions during the I Workshop of Species Distribution Modeling, in Jataí, Goiás, July/2012. Our research about the effects of climate change on Brazilian Cerrado species is part of the research network GENPAC (Geographical Genetics and Regional Planning for natural resources in Brazilian Cerrado), supported by CAPES, CNPq and FAPEG (projects n. 564717/2010-0, 563727/2010-1 and 563624/2010-8). Development of Bioensembles platform was supported by grants and fellowships from BBVA foundation and MCT/ $\mathrm{CNPq}$ in the "Rede Clima" research network. Research by 
MBA, FG, JAFD-F, and TFR is partly supported through FCT Range Shift (PTDC/AAC-AMB/98163/2008) project. Work by JAFD-F, TFR, RGC and MPCT have been continuously supported by CNPq productivity grants.

\section{References}

Araújo MB et al., 2008. Quaternary climate changes explain diversity among reptiles and amphibians. Ecography, 31:8-15. http://dx.doi.org/10.1111/j.2007.0906-7590.05318.x

Araújo MB et al., 2011. Climate change threatens European conservation areas. Ecology Letters, 14:484-492. PMid:21447141 PMCid:3116148. http://dx.doi. org/10.1111/j.1461-0248.2011.01610.x

Araújo MB \& New M, 2007. Ensemble forecasting of species distributions. Trends in ecology \& evolution, 22:42-7. PMid:17011070. http://dx.doi.org/10.1016/j.tree.2006.09.010

Araújo MB \& Peterson AT, 2012. Uses and misuses of bioclimatic envelope modeling. Ecology, 93:1527-1539. PMid:22919900. http://dx.doi.org/10.1890/11-1930.1

Ashcroft MB, 2010. Identifying refugia from climate change. Journal of Biogeography, 37:1407-1413.

Beaumont LJ, Hughes L \& Poulsen M, 2005. Predicting species distributions: use of climatic parameters in BIOCLIM and its impact on predictions of species' current and future distributions. Ecological Modelling, 186:251-270. http:// dx.doi.org/10.1016/j.ecolmodel.2005.01.030

Collevatti et al., 2012a. Recovering the demographical history of a Brazilian savanna tree species Caryocar brasiliense: coupling ecological niche modeling and coalescent analyses. Natureza \& Conservação, 10(2): 169-176. http://dx.doi. org/10.4322/natcon.2012.024

Collevatti RG et al., 2012b. Drawbacks to palaeodistribution modelling: the case of South American seasonally dry forests. Journal of Biogeography. In press. Available from: $<$ http://wileyonlinelibrary.com/journal/jbi>.

Diniz-Filho JAF et al., 2009. Partitioning and mapping uncertainties in ensembles of forecasts of species turnover under climate change. Ecography, 32:897-906. http://dx.doi. org/10.1111/j.1600-0587.2009.06196.x

Diniz-Filho JAF et al., 2010. Ensemble forecasting shifts in climatically suitable areas for Tropidacris cristata (Orthoptera: Acridoidea: Romaleidae). Insect Conservation and Diversity, 3(3):213-221. http://dx.doi. $\operatorname{org} / 10.1111 / \mathrm{j} .1752-4598.2010 .00090 . \mathrm{x}$

Food and Agriculture Organization of the United Nations - FAO et al., 2009. Harmonized World Soil Database. (version1.1). Rome: FAO; Laxenburg: IIASA.

Fjeldså J, Lambin E \& Mertens B, 1999. Correlation between endemism and local ecoclimatic stability documented by comparing Andean bird distributions and remotely sensed land surface data. Ecography, 22:63-78. http://dx.doi. org/10.1111/j.1600-0587.1999.tb00455.x

Garcia R et al., 2012. Exploring consensus in 21st century projections of climatically suitable areas for African vertebrates. Global Change Biology, 18:1253-1269. http:// dx.doi.org/10.1111/j.1365-2486.2011.02605.x

Giovanni R et al., 2012. The real task of selecting records for ecological niche modeling. Natureza \& Conservação, 10(2): 139-144. http://dx.doi.org/10.4322/natcon.2012.018

Graham CH, Moritz C \& Williams SE, 2006. Habitat history improves prediction of biodiversity in rainforest fauna. Proceedings of the National Academy of Sciences, 103:632-636. PMid:16407139 PMCid:1334636. http://dx.doi.org/10.1073/ pnas. 0505754103

Graham CH et al., 2010. Dynamic refugia and species persistence: tracking spatial shifts in habitat through time. Ecography, 33:1062-1069. http://dx.doi. org/10.1111/j.1600-0587.2010.06430.x

Haffer J, 1969. Speciation in Amazonian forest birds. Science, 165:131-137. PMid:17834730. http://dx.doi. org/10.1126/science.165.3889.131

Hannah L et al., 2007. Protected area needs in a changing climate. Frontiers in Ecology and the Environment, 5:131-138. http:// dx.doi.org/10.1890/1540-9295(2007)5[131:PANIAC]2.0.CO;2

Heikkinen RK et al., 2006. Methods and uncertainties in bioclimatic envelope modelling under climate change. Progress in Physical Geography 30:751-777. http://dx.doi org/10.1177/0309133306071957

Loyola et al., 2012. Severe loss of suitable climatic conditions for marsupial species in brazil: challenges and opportunities for conservation. PlosOne, 7:1-9. PMid:23029452 PMCid:3460884. http://dx.doi.org/10.1371/journal. pone. 0046257

Munguía M et al., 2012. Equilibrium of global amphibian species distributions with climate. PlosOne, 7:e34420. PMid:22511938 PMCid:3325238. http://dx.doi.org/10.1371/ journal.pone.0034420

Nenzén HK \& Araújo MB, 2011. Choice of threshold alters projections of species range shifts under climate change. Ecological Modelling, 222:3346-3354. http://dx.doi. org/10.1016/j.ecolmodel.2011.07.011

Nogués-Bravo D et al., 2008. Climate change, humans, and the extinction of the Woolly Mammoth. PLoS Biology, 6:e79. PMid:18384234 PMCid:2276529. http://dx.doi.org/10.1371/ journal.pbio.0060079

Pearson RG et al., 2006. Model-based uncertainty in species range prediction. Journal of Biogeography, 33:1704-1711. http://dx.doi.org/10.1111/j.1365-2699.2006.01460.x

Peterson AT \& Soberon J, 2012. Species Distribution Modeling and Ecological Niche Modeling: Getting the Concepts Right. Natureza \& Conservação, 10(2): 102-107. http:// dx.doi.org/10.4322/natcon.2012.019

Peterson AT et al., 2011. Ecological Niches and Geographical Distributions. Princeton: Princeton University Press. Monographs in Population Biology 49.

Ratter JA, Bridgewater S \& Ribeiro JF, 2003. Analysis of the floristic composition of the Brazilian cerrado vegetation iii: comparison of the woody vegetation of 376 areas 
Edinburgh Journal of Botany, 60:57-109. http://dx.doi. org/10.1017/S0960428603000064

Santika T, 2011. Assessing the effect of prevalence on the predictive performance of species distribution models using simulated data. Global Ecology and Biogeography, 20: 181-192. http://dx.doi.org/10.1111/j.1466-8238.2010.00581.x

Smith FA \& Boyer AG, 2012. Losing time? Incorporating a deeper temporal perspective into modern ecology. Frontiers of Biogeography, 4.1:26-39.

Werneck FP et al., 2012. Climatic stability in the Brazilian Cerrado: implications for biogeographical connections of South
American savannas, species richness and conservation in a biodiversity hotspot. Journal of Biogeography, 39:1695-1706. http://dx.doi.org/10.1111/j.1365-2699.2012.02715.x

Williams JW \& Jackson ST, 2007. Novel climates, no-analog communities, and ecological surprises. Frontiers in Ecologyand the Environment, 5:475-482. http://dx.doi. org/10.1890/070037

Williams SE et al., 2008. Towards an integrated framework for assessing the vulnerability of species to climate change. Plos Biology, 6:2621-2626. http://dx.doi.org/10.1371/journal. pbio.0060325

Received: October 2012

First Decision: October 2012

Accepted: November 2012 